\section{Low back pain in youth: Recognizing red flags}

\section{Although low back pain in children and teens is usually benign, recognizing red flags that indicate the need for imaging, referral, bracing, or surgery is critical.}

$\mathrm{L}$ ow back pain in not uncommon in children and adolescents. ${ }^{1-3}$ Although the prevalence of low back pain in children $<7$ years is low, it increases with age, with studies reporting lifetime prevalence at age 12 years between $16 \%$ and $18 \%$ and rates as high as $66 \%$ by 16 years of age. ${ }^{4,5}$ Although children and adolescents usually have pain that is transient and benign without a defined cause, structural causes of low back pain should be considered in school-aged children with pain that persists for $>3$ to 6 weeks. ${ }^{4}$ The most common structural causes of adolescent low back pain are reviewed here.

\section{Etiology: A mixed bag}

Back pain in school-aged children is most commonly due to muscular strain, overuse, or poor posture. The pain is often transient in nature and responds to rest and postural education. ${ }^{4,6}$ A herniated disc is an uncommon finding in younger school-aged children, but incidence increases slightly among older adolescents, particularly those who are active in collision sports and/or weight-lifting. ${ }^{7,8}$ Pain caused by a herniated disc often radiates along the distribution of the sciatic nerve and worsens during lumbar flexion.

I Spondylolysis and spondylolisthesis are important causes of back pain in children. Spondylolysis is defined as a defect or abnormality of the pars interarticularis and surrounding lamina and pedicle. Spondylolisthesis, which is less common, is defined as the translation or "slippage" of one vertebral segment in relation to the next caudal segment. These conditions commonly occur as a result of repetitive stress.

In a prospective study of adolescents $<19$ years with low back pain for $>2$ weeks, the prevalence of spondylolysis was $39.7 \% .^{9}$ Adolescent athletes with symptomatic low back pain are more likely to have spondylolysis than nonathletes $(32 \%$ vs $2 \%$, respectively). ${ }^{2,10}$ Pain is often made worse by extension of the spine. Spondylolysis and spondylolisthesis can be congenital or acquired, and both can be asymptomatic. Children
Shawn F. Phillips, MD, MSPT; Jessica Favero Butts, MD; Matthew Silvis, MD Department of Family and Community Medicine, Penn State College of Medicine and Penn State Health Milton S. Hershey Medical Center, Hershey

\section{Dsphillips6@pennstatehealth psu.edu.}

The authors reported no potential conflict of interest relevant to this article.

doi: $10.12788 /$ jp. 0076 


\section{$>$}

Hyperextension in a singleleg stance, commonly known as the Stork test, is positive for unilateral spondylolysis when it reproduces pain on the ipsilateral side. and teens who are athletes are at higher risk for symptomatic spondylolysis and spondylolisthesis. ${ }^{10-12}$ This is especially true for those involved in gymnastics, dance, football, and/ or volleyball, where a repetitive load is placed onto an extended spine.

I Idiopathic scoliosis is an abnormal lateral curvature of the spine that usually develops during adolescence and worsens with growth. Historically, painful scoliosis was considered rare, but more recently researchers determined that children with scoliosis have a higher rate of pain compared to their peers. ${ }^{13,14}$ School-aged children with scoliosis were found to be at 2 times the risk of low back pain compared to those without scoliosis. ${ }^{13}$ It is important to identify scoliosis in adolescents so that progression can be monitored.

Screening for scoliosis in primary care is somewhat controversial. The US Preventive Services Task Force (USPSTF) finds insufficient evidence for screening asymptomatic adolescents for scoliosis. ${ }^{15}$ This recommendation is based on the fact that there is little evidence on the effect of screening on longterm outcomes. Screening may also lead to unnecessary radiation. Conversely, a position statement released by the Scoliosis Research Society, the Pediatric Orthopedic Society of North America, the American Association of Orthopedic Surgeons, and the American Academy of Pediatrics recommends scoliosis screening during routine pediatric office visits. ${ }^{16}$ Screening for girls is recommended at ages 10 and 12 years, and for boys, once between ages 13 and 14 years. The statement highlights evidence showing that focused screening by appropriate personnel has value in detecting a clinically significant curve $\left(>20^{\circ}\right)$.

I Scheuermann disease is a rare cause of back pain in children that usually develops during adolescence and results in increasing thoracic kyphosis. An autosomal dominant mutation plays a role in this disease of the growth cartilage endplate; repetitive strain on the growth cartilage is also a contributing factor. ${ }^{17,18}$ An atypical variant manifests with kyphosis in the thoracolumbar region. ${ }^{17}$

I Other causes of low back pain-including inflammatory arthritis, infection (eg, discitis), and tumor-are rare in children but must always be considered, especially in the setting of persistent symptoms. ${ }^{4,19-21}$ More on the features of these conditions is listed in TABLE 1. 1-7,13-15,17-30

\section{History: Focus on onset, timing, and duration of symptoms}

As with adults, obtaining a history that includes the onset, timing, and duration of symptoms is key in the evaluation of low back pain in children, as is obtaining a history of the patient's activities; sports that repetitively load the lumbar spine in an extended position increase the risk of injury. ${ }^{10}$

Specific risk factors for low back pain in children and adolescents are poorly understood. ${ }^{4,9,31}$ Pain can be associated with trauma, or it can have a more progressive or insidious onset. Generally, pain that is present for up to 6 weeks and is intermittent or improving has a self-limited course. Pain that persists beyond 3 to 6 weeks or is worsening is more likely to have an anatomical cause that needs further evaluation. . $, 3,10,21^{2}$

I Identifying exacerbating and alleviating factors can provide useful information. Pain that is worse with lumbar flexion is more likely to come from muscular strain or disc pathology. Pain with extension is more likely due to a structural cause such as spondylolysis/spondylolisthesis, scoliosis, or Scheuermann disease. ., $, 10,17,18,21$ See TABLE 2 for red flag symptoms that indicate the need for imaging and further work-up.

\section{The physical exam: Visualize, assess} range of motion, and reproduce pain

The physical examination of any patient with low back pain should include direct visualization and inspection of the back, spine, and pelvis; palpation of the spine and paraspinal regions; assessment of lumbar range of motion and of the lumbar nerve roots, including tests of sensation, strength, and deep tendon reflexes; and an evaluation of the patient's posture, which can provide clues to underlying causes of pain.

Increased thoracic kyphosis that is not reversible is concerning for Scheuermann disease. ${ }^{9,17,18}$ A significant elevation in one shoulder or side of the pelvis can be indicative of scoliosis. Increased lumbar lordosis 
TABLE 1

\section{Common causes of low back pain in children and adolescents}

\begin{tabular}{|c|c|c|c|}
\hline Condition & Definition & Prevalence & Treatment \\
\hline Mechanical low back pain ${ }^{1,4}$ & $\begin{array}{l}\text { Low back pain that does } \\
\text { not always have a clear } \\
\text { anatomical cause. Often } \\
\text { associated with muscle strain, } \\
\text { overuse, or poor posture }\end{array}$ & $\begin{array}{l}\text { Most common form of } \\
\text { low back pain in children } \\
\text { and adolescents. Increases } \\
\text { in prevalence with age. } \\
\text { Reported prevalence is } 16 \% \text { - } \\
66 \% 4,5\end{array}$ & $\begin{array}{l}\text { Treatment is generally } \\
\text { conservative. Relative rest } \\
\text { from activities that increase } \\
\text { pain. Physical therapy may be } \\
\text { indicated if pain is persistent }\end{array}$ \\
\hline $\begin{array}{l}\text { Adolescent idiopathic } \\
\text { scoliosis }^{13-15,28-30}\end{array}$ & $\begin{array}{l}\text { An abnormal lateral } \\
\text { curvature of the spine that } \\
\text { usually develops during } \\
\text { adolescence and worsens } \\
\text { with growth }\end{array}$ & $\begin{array}{l}\text { Reported prevalence of } \\
\text { scoliosis is } 2 \%-4 \% \text {. Prevalence } \\
\text { of pain associated with } \\
\text { scoliosis ranges from } 34.7 \% \text { - } \\
42 \%^{28}\end{array}$ & $\begin{array}{l}\text { Little evidence exists to } \\
\text { guide treatment of back } \\
\text { pain associated with scoliosis. } \\
\text { Treatment similar to that for } \\
\text { nonspecific mechanical low back } \\
\text { pain is reasonable in patients } \\
\text { with curvature }<20^{\circ} \text {. Limited } \\
\text { evidence shows benefit for } \\
\text { physical therapy and bracing } \\
\text { in preventing progression of } \\
\text { curvature. Referral to Pediatric } \\
\text { Orthopedics is indicated for } \\
\text { Cobb angle } \geq 20^{\circ} \text {. Cobb angle } \\
10-19^{\circ} \text { can be monitored by the } \\
\text { family physician with repeat } \\
\text { imaging every } 6-12 \text { months }\end{array}$ \\
\hline $\begin{array}{l}\text { Spondylolysis and } \\
\text { spondyolysthesis }^{2,3,24-27}\end{array}$ & $\begin{array}{l}\text { Spondylolysis is a defect of } \\
\text { the pars interarticularis and } \\
\text { surrounding lamina and } \\
\text { pedicle. Spondylolisthesis } \\
\text { is translation or "slippage" } \\
\text { of one vertebral segment in } \\
\text { relation to the next caudal } \\
\text { segment. It is a result of } \\
\text { repetitive stress with the } \\
\text { spine moving into extension }\end{array}$ & $\begin{array}{l}\text { Prevalence of spondylolysis is } \\
39.7 \% .{ }^{6} \text { Adolescent athletes } \\
\text { with symptomatic low } \\
\text { back pain are more likely } \\
\text { to have spondylolysis than } \\
\text { nonathletes ( } 32 \% \text { vs } 2 \% \text {, } \\
\text { respectively) }{ }^{7}\end{array}$ & $\begin{array}{l}\text { Relative rest from activity is } \\
\text { recommended for } 4-6 \text { weeks. } \\
\text { Rehabilitation with range- } \\
\text { of-motion (especially into } \\
\text { lumbar extension) and spinal } \\
\text { stabilization exercises have } \\
\text { been shown to be effective } \\
\text { treatments to both reduce pain } \\
\text { and restore functional range } \\
\text { of motion and strength. }{ }^{22,23} \text { Use } \\
\text { of heavy backpacks should be } \\
\text { avoided }\end{array}$ \\
\hline Scheuermann disease $\mathrm{e}^{17,18}$ & $\begin{array}{l}\text { Increased thoracic kyphosis } \\
\text { due to autosomal dominant } \\
\text { mutation affecting collagen } \\
\text { matrix leading to disease } \\
\text { of the growth cartilage } \\
\text { endplate. Classic imaging } \\
\text { finding is Schmorl nodes }\end{array}$ & Reported prevalence is $2.8 \%{ }^{17}$ & $\begin{array}{l}\text { Avoid repetitive loading of } \\
\text { the spine including overhead } \\
\text { weight-lifting and sports such } \\
\text { as football and gymnastics. } \\
\text { Physical therapy is indicated for } \\
\text { persistent pain }\end{array}$ \\
\hline
\end{tabular}

may predispose a patient to spondylolysis.

In patients with spondylolysis, lumbar extension will usually reproduce pain, which is often unilateral. Hyperextension in a single-leg stance, commonly known as the Stork test, is positive for unilateral spondylolysis when it reproduces pain on the ipsilateral side. The sensitivity of the Stork test for unilateral spondylolysis is approximately $50 \%{ }^{32}$ (For more information on the Stork test, see
www.physio-pedia.com/Stork_test.)

Pain reproduced with lumbar flexion is less concerning for bony pathology and is most often related to soft-tissue strain. Lumbar flexion with concomitant radicular pain is associated with disc pathology. ${ }^{8}$ Pain with a straight-leg raise is also associated with disk pathology, especially if raising the contralateral leg increases pain. ${ }^{8}$

I Using a scoliometer. Evaluate the 
TABLE 1

\section{Common causes of low back pain in children and adolescents (cont'd)}

\begin{tabular}{|c|c|c|c|}
\hline Condition & Definition & Prevalence & Treatment \\
\hline Tumor 20 & $\begin{array}{l}\text { Benign tumors include } \\
\text { vertebral hemangioma and } \\
\text { osteoid osteoma. Malignant } \\
\text { tumors include Ewing } \\
\text { sarcoma, chondroma, and } \\
\text { osteosarcoma. Patients } \\
\text { present with persistent } \\
\text { worsening of back pain, } \\
\text { despite rest. Patients can } \\
\text { present with red flag } \\
\text { symptoms }\end{array}$ & $\begin{array}{l}\text { Rare. Often discovered on } \\
\text { imaging in patients with red } \\
\text { flag symptoms }\end{array}$ & $\begin{array}{l}\text { Referral to orthopedic } \\
\text { oncologist is appropriate }\end{array}$ \\
\hline Infection ${ }^{19}$ & $\begin{array}{l}\text { Infection of the lumbar } \\
\text { spine can include discitis, } \\
\text { osteomyelitis, and spondylitis. } \\
\text { Most commonly caused } \\
\text { by Staphylococcus aureus } \\
\text { infection. Patients will } \\
\text { present with back pain that is } \\
\text { not improving. Patients may } \\
\text { also present with red flag } \\
\text { symptoms such as fever, chills, } \\
\text { night sweats, night-time } \\
\text { awakenings, and weight loss }\end{array}$ & $\begin{array}{l}\text { Rare, approximately } \\
1 / 250,000 .{ }^{19} \text { Usually } \\
\text { discovered on imaging studies } \\
\text { in patients with red flag } \\
\text { symptoms }\end{array}$ & $\begin{array}{l}\text { Inpatient admission; } \\
\text { consultation of Pediatric } \\
\text { Orthopedics and Infectious } \\
\text { Disease }\end{array}$ \\
\hline Spondyloarthropathy ${ }^{21}$ & $\begin{array}{l}\text { Inflammatory arthropathy } \\
\text { due to several rheumatologic } \\
\text { diseases including HLA-B27- } \\
\text { positive juvenile ankylosing } \\
\text { spondylitis, psoriatic arthritis, } \\
\text { and reactive arthritis }\end{array}$ & $\begin{array}{l}\text { Rare. Patients often present } \\
\text { with persistent pain. Morning } \\
\text { stiffness lasting }>30 \text { minutes } \\
\text { is common }\end{array}$ & $\begin{array}{l}\text { Referral to Rheumatology. } \\
\text { Treatment with anti- } \\
\text { inflammatory medication, tumor } \\
\text { necrosis factor-alpha inhibitors }\end{array}$ \\
\hline
\end{tabular}

flexed spine for the presence of asymmetry, which can indicate scoliosis. ${ }^{33}$ If asymmetry is present, use a scoliometer to determine the degree of asymmetry. Zero to $5^{\circ}$ is considered clinically insignificant; monitor and reevaluate these patients at subsequent visits. ${ }^{34,35} \mathrm{Ten}$ degrees or more of asymmetry with a scoliometer should prompt you to order radiographs. ${ }^{35,36} \mathrm{~A}$ smartphone-based scoliometer for iPhones was evaluated in 1 study and was shown to have reasonable reliability and validity for clinical use. ${ }^{37}$

I Deformity of the lower extremities. Because low back pain may be caused by biomechanical or structural deformity of the lower extremities, examine the flexibility of the hip flexors, gluteal musculature, hamstrings, and the iliotibial band ${ }^{38}$ In addition, evaluate for leg-length discrepancy and lower-extremity malalignment, such as femoral anteversion, tibial torsion, or pes planus.

\section{Imaging:}

\section{Know when it's needed}

Although imaging of the lumbar spine is often unnecessary in the presence of acute low back pain in children, always consider imaging in the setting of bony tenderness, pain that wakes a patient from sleep, and in the setting of other red flag symptoms (see TABLE 2). Low back pain in children that is reproducible with lumbar extension is concerning for spondylolysis or spondylolisthesis. If the pain with extension persists beyond 3 to 6 weeks, order imaging starting with radiographs. ${ }^{2,39}$

Traditionally, 4 views of the spineanteroposterior (AP), lateral, and oblique (one right and one left)-were obtained, but recent evidence indicates that 2 views (AP and lateral) have similar sensitivity and specificity to 4 views with significantly reduced radiation exposure. ${ }^{2,39}$ Because the sensitivity 
TABLE 2

\section{Red flags that indicate the need for imaging}

- Fever, chills

- Skin infection

- Penetrating wound near spine

- Trauma

- Unrelenting night pain or pain at rest

- Morning stiffness lasting > 30-60 minutes

- Progressive motor or sensory deficit

- Failure to improve after 3 to 6 weeks of conservative therapy

- Saddle anesthesia, bilateral sciatica, or leg weakness; difficulties urinating or bowel incontinence (concerning for Cauda equina syndrome)

- Unexplained weight loss

- History of, or strong suspicion for, cancer

- Immunosuppression

- Chronic oral steroid use

- Intravenous drug abuse

of plain films is relatively low, consider more advanced imaging if spondylolysis or spondylolisthesis is strongly suspected. Recent studies indicate that magnetic resonance imaging (MRI) may be as effective as computed tomography (CT) or bone scan and has the advantage of lower radiation (FIGURE 1).,22

Similarly, order radiographs if there is $>10^{\circ}$ of asymmetry noted on physical exam using a scoliometer. ${ }^{15,23}$ Calculate the Cobb angle to determine the severity of scoliosis. Refer patients with angles $\geq 20^{\circ}$ to a pediatric orthopedist for monitoring of progression and consideration of bracing (FIGURE 2). ${ }^{23,34}$ For patients with curvatures between $10^{\circ}$ and $19^{\circ}$, repeat imaging every 6 to 12 months. Because scoliosis is a risk factor for spondylolysis, evaluate radiographs in the setting of painful scoliosis for the presence of a spondylolysis. ${ }^{34,35}$

If excessive kyphosis is noted on exam, order radiographs to evaluate for Scheuermann disease. Classic imaging findings include Schmorl nodes, vertebral endplate changes, and anterior wedging (FIGURE 3). ${ }^{17,18}$

In the absence of the above concerns, defer imaging of the lumbar spine until after

\section{FIGURE 1}

\section{Spondylolysis on MRI}

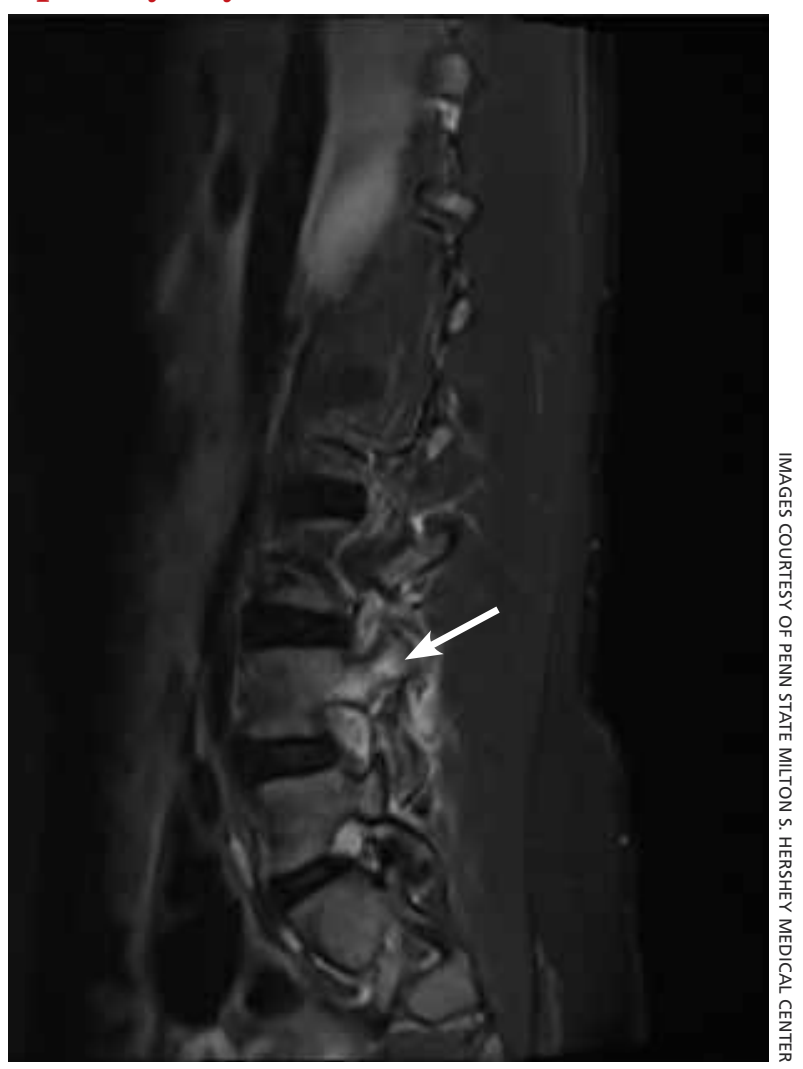

This magnetic resonance imaging scan shows a pars interarticularis defect at L4 on the left side, consistent with spondylolysis (arrow).

adequate rest and rehabilitation have been attempted.

\section{Treatment typically involves rest or physical therapy}

Most cases of low back pain in children and adolescents are benign and self-limited. Many children with low back pain can be treated with relative rest from the offending activity. For children with more persistent pain, physical therapy (PT) is often indicated. Similar to that for adults, there is little evidence for specific PT programs to help children with low back pain. Rehabilitation should be individualized based on the condition being treated.

I Medications. There have been no highquality studies on the benefit of medications to treat low back pain in children. Studies have shown nonsteroidal anti-inflammatory drugs (NSAIDs) have value in adults, and they 


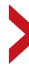

Pain reproduced with lumbar flexion is less concerning for bony pathology and is most often related to soft-tissue strain.

\section{FIGURE 2}

Right thoracic scoliotic curvature with Cobb angle of $\approx 46^{\circ}$

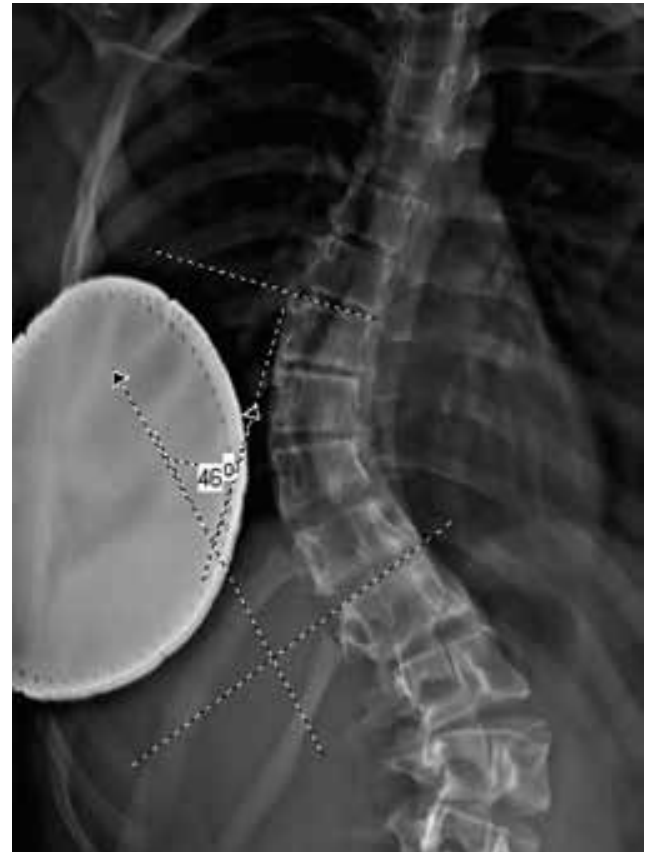

are likely safe for use in children, ${ }^{40}$ but the risk of opiate abuse is significantly increased in adolescents who have been prescribed opiate pain medication prior to 12 th grade. ${ }^{41}$

I Lumbar disc herniation. Although still relatively rare, lumbar disc herniation is more common in older children and adolescents than in younger children and is treated similarly to that in adults. ${ }^{8}$ Range-of-motion exercise to restore lumbar motion is often first-line treatment. Research has shown that exercises that strengthen the abdominal or "core" musculature help prevent the return of low back pain. ${ }^{24,25}$

In the case of spondylolysis or spondylolisthesis, rest from activity is generally required for a minimum of 4 to 6 weeks. Rehabilitation in the form of range of motion, especially into the lumbar extension, and spinal stabilization exercises are effective for both reducing pain and restoring rangeof-motion and strength. ${ }^{42}$ Have patients avoid heavy backpacks, which can reproduce pain. Children often benefit from leaving a second set of schoolbooks at home. For most patients
FIGURE 3

\section{Radiograph reveals \\ Scheuermann disease}

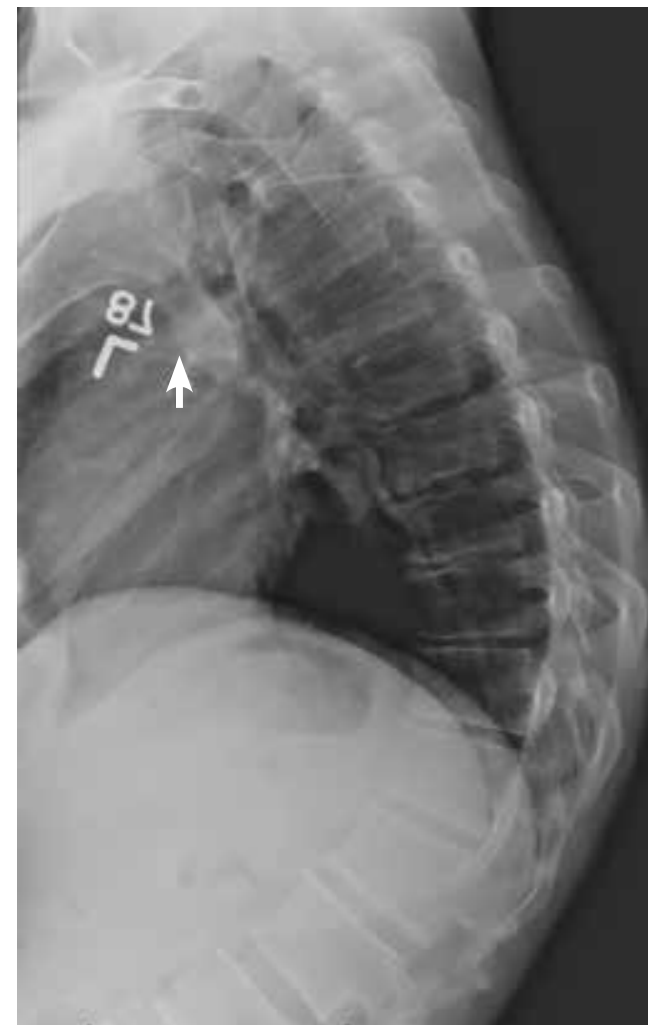

This radiograph of a patient with Scheuermann disease reveals severe kyphosis and vertebral body end-plate changes (arrow).

with spondylolysis, conservative treatment with rehabilitation is equal to or better than surgical intervention in returning the patient to his/her pre-injury activity level. ${ }^{26,43,44}$ When returning athletes to their sport, aggressive PT, defined as rest for $<10$ weeks prior to initiating PT, is superior to delaying PT beyond 10 weeks of rest. ${ }^{27}$

Idiopathic scoliosis. Much of the literature on the treatment of scoliosis is focused on limiting progression of the scoliotic curvature. Researchers thought that more severe curves were associated with more severe pain, but a recent systematic review showed that back pain can occur in patients with even small curvatures. ${ }^{28}$ Treatment for patients with smaller degrees of curvature is similar to that for mechanical low back pain. PT may have a role in the treatment of scoliosis, but there is little evidence in the literature of its effectiveness. 
A Cochrane review showed that PT and exercise-based treatments had no effect on back pain or disability in patients with scoliosis. ${ }^{29}$ And outpatient PT alone, in the absence of bracing, does not arrest progression of the scoliotic curvature. ${ }^{35}$ One trial did demonstrate that an intensive inpatient treatment program of 4 to 6 weeks for patients with curvature of at least $40^{\circ}$ reduced progression of curvature compared to an untreated control group at 1 year. ${ }^{34}$ The outcomes of functional mobility and pain were not measured. Follow-up data on curve progression beyond 1 year are not available. Unfortunately, intensive inpatient treatment is not readily available or cost-effective for most patients with scoliosis.

I Scheuermann disease. The mainstay of treatment for mild Scheuermann disease is advising the patient to avoid repetitive loading of the spine. Patients should avoid sports such as competitive weight-lifting, gymnastics, and football. Lower impact athletics are encouraged. Refer patients with pain to PT to address posture and core stabilization. Patients with severe kyphosis may require surgery. ${ }^{17,18}$

\section{Bracing: Rarely helpful for low back pain}

The use of lumbar braces or corsets is rarely helpful for low back pain in children. Bracing in the setting of spondylolysis is controversial. One study indicated that bracing in combination with activity restriction and lumbar extension exercise is superior to activity restriction and lumbar flexion exercises alone. ${ }^{43}$ But a meta-analysis did not demonstrate a significant difference in recovery when bracing was added ${ }^{44}$ Bracing may help to reduce pain initially in patients with spondylolysis who have pain at rest. Bracing is not recommended for patients with pain that abates with activity modification.

I Scoliosis and Scheuermann kyphosis. Treatment of adolescent idiopathic scoliosis usually consists of observation and periodic reevaluation. Bracing is a mainstay of the nonsurgical management of scoliosis and is appropriate for curves of $20^{\circ}$ to $40^{\circ}$; studies have reported successful control of curve progression in $>70 \%$ of patients. ${ }^{36}$ According to 1 study, the number of cases of scoliosis needed to treat with bracing to prevent 1 surgery is $3{ }^{30}$ Surgery is often indicated for patients with curvatures $>40^{\circ}$, although this is also debated. ${ }^{33}$

Bracing is used rarely for Scheuermann kyphosis but may be helpful in more severe or painful cases. ${ }^{17}$

JFP

\section{CORRESPONDENCE}

Shawn F. Phillips, MD, MSPT, 500 University Drive H154, Hershey, PA, 17033; sphillips6@pennstatehealth.psu.edu.

\section{References}

1. MacDonald J, Stuart E, Rodenberg R. Musculoskeletal low back pain in school-aged children: a review. JAMA Pediatr. 2017;171:280-287

2. Tofte JN CarlLee TL, Holte AJ, et al. Imaging pediatric spondylolysis: a systematic review. Spine. 2017;42:777-782.

3. Sakai T, Sairyo K, Suzue N, et al. Incidence and etiology of lumbar spondylolysis: review of the literature. J Orthop Sci. 2010;15: 281-288.

4. Calvo-Muñoz I, Gómez-Conesa A, Sánchez-Meca J. Prevalence of low back pain in children and adolescents: a meta-analysis. $B M C$ Pediatrics. 2013;13:14.

5. Bernstein RM, Cozen H. Evaluation of back pain in children and adolescents. Am Fam Physician. 2007;76:1669-1676.

6. Taxter AJ, Chauvin NA, Weiss PF. Diagnosis and treatment of low back pain in the pediatric population. Phys Sportsmed. 2014;42:94-104.

7. Haus BM, Micheli LJ. Back pain in the pediatric and adolescent athlete. Clin Sports Med. 2012;31:423-440.

8. Lavelle WF, Bianco A, Mason R, et al. Pediatric disk herniation. JAm Acad Orthop Surg. 2011;19:649-656.

9. Taimela S, Kujala UM, Salminen JJ, et al. The prevalence of low back pain among children and adolescents: a nationwide, cohort-based questionnaire survey in Finland. Spine. 1997;22 1132-1136.

10. Schroeder GD, LaBella CR, Mendoza M, et al. The role of in tense athletic activity on structural lumbar abnormalities in adolescent patients with symptomatic low back pain. Eur Spine J. 2016;25:2842-2848.

11. Waicus KM, Smith BW. Back injuries in the pediatric athlete. Curr Sports Med Rep. 2002;1:52-58.

12. Daniels JM, Pontius G, El-Amin S, et al. Evaluation of low back pain in athletes. Sports Health. 2011;3:336-345.

13. Sato T, Hirano T, Ito T, et al. Back pain in adolescents with idiopathic scoliosis: epidemiological study for 43,630 pupils in $\mathrm{Ni}$ igata City, Japan. Eur Spine J. 2011;20:274-279.

14. Smorgick Y, Mirovsky Y, Baker KC, et al. Predictors of back pain in adolescent idiopathic scoliosis surgical candidates. J Pediatr Orthop. 2013;33:289-292.

15. US Preventive Services Task Force. Screening for Adolescent Idiopathic Scoliosis. US Preventive Services Task Force Recommendation Statement. JAMA. 2018;319:165-172.

16. Hresko MT, Talwalkar VR, Schwend RM. Position statementScreening for the early detection of idiopathic scoliosis in adolescents. SRS/POSNA/AAOS/AAP Position Statement. 2015. www.srs.org/about-srs/news-and-announcements/positionstatement---screening-for-the-early-detection-for-idiopathicscoliosis-in-adolescents. Accessed September 30, 2020.

17. Palazzo C, Sailhan F, Revel M. Scheuermann's disease: an update Joint Bone Spine. 2014;81:209-214.

18. Ali RM, Green DW, Patel TC. Scheuermann's kyphosis. Curr Opin Pediatr. 1999;11:70-75.

19. de Moraes Barros Fucs PM, Meves R, Yamada HH, et al. Spinal infections in children: a review. Int Orthop. 2012;36:387-395.

20. Joaquim AF, Ghizoni E, Valadares MG, et al. Spinal tumors in children. Revista da Associação Médica Brasileira. 2017;63:459-465.

CONTINUED
Always consider imaging in the setting of bony tenderness, pain that wakes the patient from sleep, and when there is $>10^{\circ}$ of asymmetry on physical exam using a scoliometer. 
21. Weiss PF, Colbert RA. Juvenile spondyloarthritis: a distinct form of juvenile arthritis. Pediatr Clin North Am. 2018;65:675-690.

22. Rush JK, Astur N, Scott S, et al. Use of magnetic resonance imaging in the evaluation of spondylolysis. J Pediatr Orthop. 2015;35: 271-275.

23. Janicki JA, Alman B. Scoliosis: review of diagnosis and treatment. Pediatr Child Health. 2007;12:771-776.

24. O'Sullivan PB, Phyty GD, Twomey LT, et al. Evaluation of specific stabilizing exercise in the treatment of chronic low back pain with radiologic diagnosis of spondylolysis or spondylolisthesis. Spine. 1997;22:2959-2967.

25. Inani SB, Selkar SP. Effect of core stabilization exercises versus conventional exercises on pain and functional status in patients with non-specific low back pain: a randomized clinical trial. J Back Musculoskelet Rehabil. 2013;26:37-43.

26. Garet M, Reiman MP, Mathers J, et al. Nonoperative treatment in lumbar spondylolysis and spondylolisthesis: a systematic review. Sports Health. 2013;5:225-232.

27. Selhorst M, Fischer A, Graft K, et al. Timing of physical therapy referral in adolescent athletes with acute spondylolysis: a retrospective chart review. Clin J Sport Med. 2017;27:296-301.

28. Théroux J, Stomski N, Hodgetts CJ, et al. Prevalence of low back pain in adolescents with idiopathic scoliosis: a systematic review. Chiropr Man Ther. 2017;25:10.

29. Romano M, Minozzi S, Zaina F, et al. Exercises for adolescent idiopathic scoliosis: a Cochrane systematic review. Spine (Phila Pa 1976). 2013;38:E883-E893.

30. Sanders JO, Newton PO, Browne RH, et al. Bracing for idiopathic scoliosis: how many patients require treatment to prevent one surgery? J Bone Joint Surg Am. 2014;96:649-653.

31. Hill JJ, Keating JL. Risk factors for the first episode of low back pain in children are infrequently validated across samples and conditions: a systematic review. J Physiother. 2010;56:237-244.

32. Grødahl LHJ, Fawcett L, Nazareth M, et al. Diagnostic utility of patient history and physical examination data to detect spondylolysis and spondylolisthesis in athletes with low back pain: a systematic review. Man Ther. 2016;24:7-17.
33. Asher MA, Burton DC. Adolescent idiopathic scoliosis: natural history and long term treatment effects. Scoliosis. 2006;1:2.

34. Weiss HR, Weiss G, Petermann F. Incidence of curvature progression in idiopathic scoliosis patients treated with scoliosis inpatient rehabilitation (SIR): an age- and sex-matched controlled study. Pediatr Rehabil. 2003;6:23-30.

35. Gomez JA, Hresko MT, Glotzbecker MP Nonsurgical management of adolescent idiopathic scoliosis. J Am Acad Orthop Surg. 2016;24:555-564.

36. Weinstein SL, Dolan LA, Wright JG, et al. Effects of bracing in adolescents with idiopathic scoliosis. N Engl J Med. 2013;369: 1512-1521.

37. Balg F, Juteau M, Theoret C, et al. Validity and reliability of the iPhone to measure rib hump in scoliosis. J Pediatr Orthop. 2014;34:774-779.

38. Auerbach JD, Ahn J, Zgonis MH, et al. Streamlining the evaluation of low back pain in children. Clin Orthop Relatl Res. 2008;466:1971-1977.

39. Beck NA, Miller R, Baldwin K, et al. Do oblique views add value in the diagnosis of spondylolysis in adolescents? J Bone Joint Surg Am. 2013;95:e65.

40. Roelofs PD, Deyo RA, Koes BW, et al. Nonsteroidal anti-inflam matory drugs for low back pain: an updated Cochrane review. Spine (Phila Pa 1976). 2008;33:1766-1774.

41. Miech R, Johnston L, O'Malley PM, et al. Prescription opioids in adolescence and future opioid misuse. Pediatrics. 2015;136:e1169-e1177.

42. Hu S, Tribus C, Diab M, et al. Spondylolysis and spondylolisthesis. J Bone Joint Surg. 2008;90:655-671.

43. Panteliadis P, Nagra NS, Edwards KL, et al. Athletic population with spondylolysis: review of outcomes following surgical repair or conservative management. Global Spine J. 2016;6: 615-625.

44. Klein G, Mehlman CT, McCarty M. Nonoperative treatment of spondylolysis and grade I spondylolisthesis in children and young adults: a meta-analysis of observational studies. J Pediatr Orthop. 2009;29:146-156. 